\title{
Simple criteria to predict prognosis in colorectal carcinoma based on lymphopenia and thrombocytosis
}

\author{
TADAHIRO NOZOE, TOMOHIRO IGUCHI, TAKASHI MAEDA, \\ MAYUKO KOHNO and TAKAHIRO EZAKI \\ Department of Surgery, Fukuoka Higashi Medical Center, Koga 811-3195, Japan
}

Received August 7, 2012; Accepted September 21, 2012

DOI: $10.3892 / \mathrm{mco} .2012 .32$

\begin{abstract}
The aim of the present study was to establish a series of criteria based on lymphopenia and thrombocytosis to determine prognosis for patients with colorectal carcinoma. Correlation of preoperative lymphopenia and thrombocytosis with clinicopathological characteristics was investigated in 215 patients with colorectal carcinoma who had undergone surgical treatment. Multivariate analysis showed that the presence of at least either lymphopenia or thrombocytosis $(\mathrm{P}=0.006)$, venous invasion $(\mathrm{P}=0.003)$ and the stage of tumors $(\mathrm{P}=0.019)$ were independent prognostic indicators. Lymphocyte percentage and platelet counts that can be determined using only data from complete blood counts may therefore serve as simple and useful tools to appropriately determine prognosis for patients with colorectal carcinoma.
\end{abstract}

\section{Introduction}

An application of the simple data of complete blood count (CBC) to predict the malignant potential of the tumor and/or prognosis of patients has been attempted.

Decrease in lymphocytes in peripheral blood means the tendency of impaired immunity of the cancer-bearing hosts (1). Therefore, previous investigations have demonstrated that the prognosis of patients with a decrease in lymphocyte counts or the lymphocyte/neutrophil ratio in peripheral blood proved to be markedly worse in carcinoma of the stomach (2), colon and rectum (3).

Moreover, an increase in the platelet in peripheral blood, i.e., thrombocytosis, has also been reported to be correlated with a more aggressive potential of malignant tumors, including colorectal carcinoma (4-6).

Correspondence to: Dr Tadahiro Nozoe, Department of Surgery, Fukuoka Higashi Medical Center, 1-1-1, Chidori, Koga 811-3195, Japan

E-mail: nozoet@fukuokae2.hosp.go.jp

Key words: colorectal carcinoma, lymphopenia, thrombocytosis, prognostic indicator
Therefore, it could be hypothesized, that the criteria to determine prognosis for patients with colorectal carcinoma should be established with a decrease in lymphocytes and an increase in the platelet in peripheral blood.

In this study, we attempted to establish some simple criteria based on lymphopenia and thrombocytosis to predict prognosis for patients with colorectal carcinoma.

\section{Patients and methods}

Patients, collection of blood samples and laboratory measurements. In total, 215 patients with colorectal carcinoma, treated by resection and lymph node dissection at the Fukuoka Higashi Medical Center (Koga, Japan) between January, 2003 and February, 2010, were included in this study. Patients with a history of malignant tumors in other organs were excluded from this study. The patients were between 24 and 90 years of age (mean, 70 years), and comprised 125 males and 90 females. No neoadjuvant therapy had been administered to patients enrolled in our study.

The blood samples were collected just prior to surgery, to measure $\mathrm{CBC}$ including lymphocyte proportion and platelet counts in the peripheral blood.

The border value of the lymphocyte proportion and platelet counts in the peripheral blood in the measuring device at our institute were estimated to be $20.0 \%$ and $35.0 \times 10^{4} / \mathrm{mm}^{2}$, respectively. Therefore, in this study, lymphocyte proportion $<20.0 \%$ and platelet counts $>35.0 \times 10^{4} / \mathrm{mm}^{2}$ were defined as lymphopenia and thrombocytosis, respectively.

The correlation of preoperative lymphopenia and thrombocytosis with the clinicopathological characteristics of the patients was investigated.

Clinicopathological characteristics. The clinicopathological characteristics were examined according to the TNM tumor stages determined by the TNM classification of malignant tumors prescribed by the International Union Against Cancer (7).

Patient follow-up. The follow-up for patients was continued until they succumbed to the disease and only patients who passed away of colorectal carcinoma were included in the tumor-related mortality. The time period between the surgery and the date of death was defined as the survival time. The 
Table I. Correlation between lymphopenia and thrombocytosis with clinical background of patients.

\begin{tabular}{|c|c|c|c|}
\hline Characteristics & $\begin{array}{l}\text { Patients with } \\
\text { either or both } \\
\quad(n=73)\end{array}$ & $\begin{array}{l}\text { Patients with } \\
\text { neither } \\
(n=142)\end{array}$ & P-value \\
\hline \multicolumn{4}{|l|}{ Gender (\%) } \\
\hline Male & $41(56.2)$ & $84(59.2)$ & \multirow[t]{2}{*}{0.674} \\
\hline Female & $32(43.8)$ & $58(40.8)$ & \\
\hline Age (years, median) & $71.3 \pm 11.2$ & $69.8 \pm 11.6$ & 0.368 \\
\hline \multicolumn{4}{|l|}{ Tumor location (\%) } \\
\hline Colon & $53(72.6)$ & $96(67.6)$ & \multirow[t]{2}{*}{0.452} \\
\hline Rectum & $20(27.4)$ & $46(32.4)$ & \\
\hline \multicolumn{4}{|l|}{ Depth of tumors $(\%)$} \\
\hline $\mathrm{T} 1,2$ & $13(17.8)$ & $53(37.3)$ & \multirow[t]{2}{*}{0.003} \\
\hline $\mathrm{T} 3,4$ & $60(82.2)$ & $89(62.7)$ & \\
\hline \multicolumn{4}{|l|}{ Histology $\mathrm{y}^{\mathrm{a}}(\%)$} \\
\hline Well & $19(26.0)$ & $49(34.5)$ & \multirow[t]{3}{*}{0.259} \\
\hline Moderate & $45(61.6)$ & $83(58.5)$ & \\
\hline Undifferentiated & $9(12.4)$ & $10(7.0)$ & \\
\hline \multicolumn{4}{|l|}{$\begin{array}{l}\text { Lymph node } \\
\text { metastasis }(\%)\end{array}$} \\
\hline No & $36(49.3)$ & $84(59.2)$ & \multirow[t]{2}{*}{0.170} \\
\hline Yes & $37(50.7)$ & $58(40.8)$ & \\
\hline \multicolumn{4}{|l|}{$\begin{array}{l}\text { Lymphatic } \\
\text { invasion }(\%)\end{array}$} \\
\hline No & $40(54.8)$ & $95(66.9)$ & \multirow[t]{2}{*}{0.082} \\
\hline Yes & $33(45.2)$ & $47(33.1)$ & \\
\hline \multicolumn{4}{|l|}{$\begin{array}{l}\text { Venous } \\
\text { invasion }(\%)\end{array}$} \\
\hline No & $55(75.3)$ & $110(77.5)$ & \multirow[t]{2}{*}{0.728} \\
\hline Yes & $18(24.7)$ & $32(22.5)$ & \\
\hline \multicolumn{4}{|l|}{ Tumor stage (\%) } \\
\hline I, II & $33(45.2)$ & $83(58.5)$ & \multirow[t]{2}{*}{0.045} \\
\hline III, IV & $40(54.8)$ & $59(41.5)$ & \\
\hline
\end{tabular}

${ }^{a}$ Well, well-differentiated adenocarcinoma; Moderate, moderately-differentiated adenocarcinoma; Undifferentiated, poorly-differentiated adenocarcinoma and mucinous carcinoma.

post-surgery follow-up interval ranged from 2 months to 7 years.

Statistical analysis. Statistical analysis was carried out using the StatView (SAS Institute Inc., Cary, NC, USA). The Chi-square test was used to compare the differences between proportion values. The Mann-Whitney test was used to compare the age of patients. Survival curves were created using the Kaplan-Meier method, while the Mantel-Cox test was used to analyze the equality of the survival curves. A Cox proportional hazards model was used in a forward stepwise manner to determine the independent prognoticators by multivariate analysis. $\mathrm{P}<0.05$ was considered to indicate a statistically significant difference.

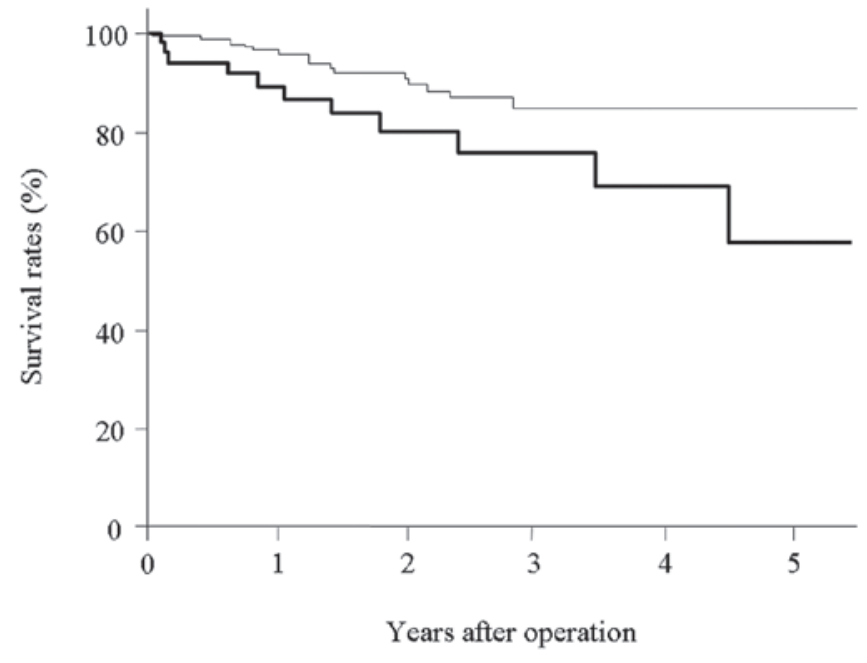

Figure 1. Survival of patients with lymphopenia (thick line) was significantly more unfavorable compared to patients without lymphopenia (thin line; $\mathrm{P}=0.012)$.

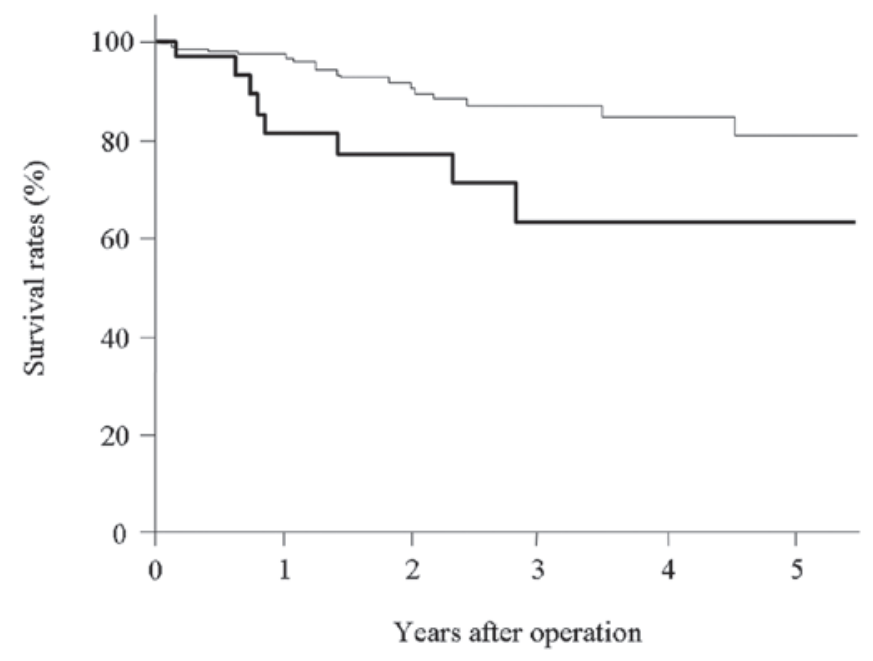

Figure 2. Survival of patients with thrombocytosis (thick line) was significantly more unfavorable compared to patients without thrombocytosis (thin line; $\mathrm{P}=0.013$ ).

\section{Results}

Univariate analysis demonstrated that survival rates of patients with lymphopenia or thrombocytosis was markedly worse compared to patients without these abnormalities, respectively $(\mathrm{P}=0.012$ and $\mathrm{P}=0.013$; Figs. 1 and 2$)$.

The clinicopathological characteristics were compared in patients with either or both lymphopenia and thrombocytosis and in patients with neither (Table I). A statistically significant difference was observed regarding depth and stage of the tumors $(\mathrm{P}=0.003$ and $\mathrm{P}=0.045$, respectively). The $1-, 3$ - and 5 -year survival rates of patients with either or both lymphopenia and thrombocytosis were $86.8,70.8$ and $60.4 \%$, respectively, markedly worse compared to patients with neither $(98.3,89.9$ and $89.9 \%$, respectively, $\mathrm{P}=0.0006$; Fig. 3 ).

Multivariate analysis demonstrated that the presence of either or both lymphopenia and thrombocytosis $(\mathrm{P}=0.006)$ as well as of factors including lymphatic invasion $(\mathrm{P}=0.009)$ and 
Table II. Factors independently correlated with prognosis.

\begin{tabular}{lccc}
\hline Variable & Regression coefficient & Odds ratio (95\% confidence interval) & P-value \\
\hline $\begin{array}{l}\text { Existence of one or both of } \\
\text { lymphopenia and thrombocytosis }\end{array}$ & 1.17 & $3.26(1.41-7.41)$ & 0.006 \\
Venous invasion & 1.27 & $3.55(1.53-8.26)$ & 0.003 \\
Stage of tumors & & $4.65(1.29-16.7)$ & 0.019 \\
(I, II vs. III, IV) & 1.54 & & \\
\hline
\end{tabular}

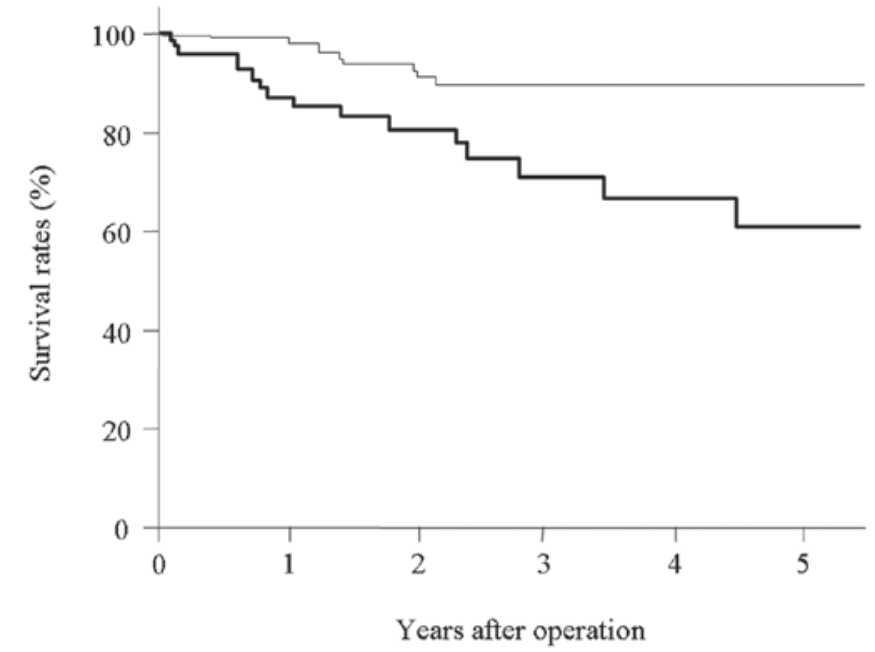

Figure 3. Survival of patients with one or both of lymphopenia and thrombocytosis (thick line) was significantly worse than that of patients with neither (thin line; $\mathrm{P}=0.0006)$.

stage of tumors $(\mathrm{P}=0.003)$ proved to be independently associated with worse prognosis for the patients (Table II).

\section{Discussion}

An infiltration of inflammatory cells including neutrophils into the tumors may promote tumor growth by the production of certain chemokines (8), whereas infiltration of lymphocyte is involved in the antitumor immune response, that may also be suppressed by neutrophils (9). Therefore a decrease in lymphocytes is likely to reflect an increase in neutrophils that might eventually be correlated with an increase of cellular aggressiveness of the tumor.

Preoperative high platelet counts have been used as indicators of an aggressive potential of the tumor and therefore prognosis of patients with digestive malignant tumors including esophageal (4), gastric (5) and colorectal carcinomas (6). Certain cytokines including pro-inflammatory cytokines, such as interleukin-1 (IL-1), IL-6, tumor necrosis factor (TNF), macrophage colony-stimulating factor and granulocyte colony-stimulating factor, are known to promote an increase in the platelet in peripheral blood, termed thrombocytosis, in tumor-bearing patients (10-12). In the present study, a significant correlation between an increase in platelet counts and preoperative serum elevation of C-reactive protein, which is also known to be upregulated by certain pro-inflammatory cytokines including IL-6 (13), was found (data not shown).
These findings demonstrate that cytokines produced by tumor growth may result in a thrombocytosis in cancer-bearing patients, which is possibly associated with an inflammatory response of the host to tumor growth. By contrast, a thrombocytosis has also been demonstrated to have the potential to promote angiogenesis, reflecting the aggressive potential of the tumors (14). Therefore it cannot be concluded whether or not an increase in the platelet in peripheral blood in tumorbearing patients is derived from tumor growth or can promote tumor growth. However, in the present study, we clearly demonstrated that a thrombocytosis may be a good indicator of the malignant potential of the tumor and the poor prognosis of patients with colorectal carcinoma.

On the basis of these findings, we hypothesized that criteria based on the combination of lymphopenia and thrombocytosis should be established to classify the prognosis of the patients with colorectal carcinoma possibly with a more strict stratification. Apart form signaling the tumor stage, the presence of either or both lymphopenia and thrombocytosis, proved to be an independent prognostic indicator in colorectal carcinoma.

In conclusion, lymphopenia and thrombocytosis may provide useful information to predict outcome in patients with colorectal carcinoma with a favorable stratification. The present study predominantly aimed to establish a series of criteria for the prognostic classification of colorectal carcinoma based on only data of CBC that can be applied in the majority of the institutes.

\section{References}

1. Nozoe T, Matsumata T and Sugimachi K: Preoperative elevation of serum C-reactive protein is related to impaired immunity in patients with colorectal cancer. Am J Clin Oncol 23: 263-266, 2000.

2. Yamanaka T, Matsumoto S, Teramukai S, Ishiwata R, Nagai Y and Fukushima M: The baseline ratio of neutrophils to lymphocytes is associated with patient prognosis in advanced gastric cancer. Oncology 73: 215-220, 2007.

3. Walsh SR, Cook EJ, Goulder F, Justin TA and Keeling NJ: Neutrophil-lymphocyte ratio as a prognostic factor in colorectal cancer. J Surg Oncol 91: 181-184, 2005.

4. Shimada H, Oohira G, Okazumi S, et al: Thrombocytosis associated with poor prognosis in patients with esophageal carcinoma. J Am Coll Surg 198: 737-741, 2004.

5. Ikeda M, Furukawa H, Imamura H, et al: Poor prognosis associated with thrombocytosis in patients with gastric cancer. Ann Surg Oncol 9: 287-291, 2002.

6. Monreal M, Fernandez-Llamazares J, Piñol M, Julian JF, Broggi M, Escola D and Abad A: Platelet count and survival in patients with colorectal cancer - a preliminary study. Thromb Haemost 79: 916-918, 1998

7. Sobin L, Gospodarowicz M, Wittekind C (eds): International Union Against Cancer. TNM classification of malignant tumours. 7th edition. Wiley-Blackwell, New York, pp 100-105, 2009. 
8. De Larco JE, Wuertz BR and Furcht LT: The potential role of neutrophils in promoting the metastatic phenotype of tumors releasing interleukin-8 . Clin Cancer Res 10: 4895-4900, 2004

9. Petrie HT, Klassen LW and Kay HD: Inhibition of human cytotoxic T lymphocyte activity in vitro by autologous peripheral blood granulocytes. J Immunol 134: 230-234, 1985.

10. Alexandrakis MG, Passam FH, Moschandrea IA, Christophoridou AV, Pappa CA, Coulocheri SA and Kyriakou D: Levels of serum cytokines and acute phase proteins in patients with essential and cancer-related thrombocytosis. Am J Clin Oncol 26: 135-140, 2003

11. Estrov Z, Talpaz M, Mavligit G, Pazdur R, Harris D, Greenberg SM and Kurzrock R: Elevated plasma thrombopoietic activity in patients with metastatic cancer-related thrombocytosis. Am J Med 98: 551-558, 1995.
12. Hollen CW, Henthorn J and Koziol JA: Serum interleukin-6 levels in patients with thrombocytosis. Leuk Lymphoma 8: 235-241, 1992.

13. Castell JV, Gómez-Lechón MJ, David M, Fabra R, Trullenque R and Heinrich PC: Acute-phase response of human hepatocytes: regulation of acute-phase protein synthesis by interleukin- 6 . Hepatology 12: 1179-1186, 1990.

14. Sierko E and Wojtukiewicz MZ: Platelets and angiogenesis in malignancy. Semin Thromb Hemost 30: 95-108, 2004. 